\section{NITRATE DEPOSITS IN THE UNITED STATES}

A PREss bulletin of the U. S. Geological Survey states that nitrate deposits in many parts of the United States have been examined during the last two years by the survey. The importance of finding a natural supply of nitrates within our own borders has given incentive to this work and has directed widespread public attention to the subject.

Prospectors in many places have raised great hopes by finding good surface showings of these salts, but investigation has seemed to force the acceptance of a general adverse judgment as to their value - a judgment that has been adopted with the greatest reluctance by all concerned. Incidentally, advantage seems to have been taken of the situation to promote certain stock-selling enterprises, even after the evidence as to the worthlessness of the deposits became sufficient to satisfy any competent judge, so that one is forced to question either the good faith of the promoters or their practical judgment.

As a result of careful study of these deposits, and particularly of evidence gathered on recent visits to prospects in different parts of the country, Mr. Hoyt S. Gale, a geologist of the Federal Survey, has submitted the following general summary, which is commended to the consideration of those who are tempted to invest their money in such enterprises.

Fine specimens of practically pure nitrate of soda and nitrate of potash (saltpeter) have been found in many parts of the country, and careful investigation of specimens and localities seems to warrant some definite conclusions as to the practical value of these deposits, especially to those who are invited to spend their money in investigations like those the survey has already made.

The nitrate salts occur as crusts or films on the faces of ledges; as seams-most of them thin, though some are fairly thick-in crevices of shattered rock; and as deposits filling spaces in porous rocks at and near the surface or extending to a depth of several feet. They are naturally preserved in recesses in the rock ledges, where they are sheltered from the dissolving action of rain, snow water, or even mist. They are found in lava ledges, in beds of volcanic tuff or ash, and in limestone and sandstone. Their existence or preservation is apparently dependent rather on the shattered or porous nature of the rock than on its kind or composition. These deposits, which have been referred to as cave or ledge deposits, are of essentially the same type wherever found, although they vary considerably in details of occurrence.

The incrustations are found not only on the faces and fractures of ledges of solid rock, but some of them form layers or cementing constituents in the loose soil and rock breccia at the bases of cliffs, or lie in places protected from the weather. Some samples obtained from both these sources are rich in nitrate salts, and analyses of such materials will bear little significant relation to the actual character or content of the mass of the rock of which the ledge is formed. It appears that the deposits are surficial-that is, they do not extend far into the mass of the rock-and the nitrate salt found is insignificant in amount.

Nitrates are found in unusually large quantities in some soils and in some clay hills, particularly in southern California. These deposits have been examined by many persons and the general conclusion reached has been unfavorable to the idea of their practical utilization. The nitrate content, although unusually large as compared with the content of ordinary soils, probably does not average over 1 or 2 per cent. of the soil or clay, and it is very doubtful whether the material could be worked commercially.

Any one who is not convinced by the judgment already reached as to these deposits and who is determined to devote his time or money to their further exploration should do so with full knowledge of the evidence already in hand and should not be led into such a venture by more or less misleading representations. The Geological Survey will always be glad to make an examination of any samples submitted.

\section{AGRICULTURE OF THE HIDATSA INDIANS}

A DOCTOR's thesis of unusual practical value is that of Dr. Gilbert L. Wilson submitted in 
June to the faculty of the University of Minnesota for the degree of Ph.D. in anthropology.

With funds largely from the American $\mathrm{Mu}$ seum of Natural History, New York, research work has been prosecuted each summer since 1910 among the Hidatsa and Mandan Indians on the Mandan Reservation, North Dakota. So important have the findings of Mr. Wilson been for probable development of a droughtresistant maize for the farmers of the northwest that both Dean A. F. Woods, of the college of agriculture, University of Minnesota, and Mr. M. L. Wilson, of the Agriculture Experiment Station, Bozeman, Montana, have contributed toward the financial support of the research.

It is interesting to learn that in western North Dakota where maize has been a doubtful crop as grown by the white farmer, the Hidatsa and Mandan Indians have for centuries been successfully cultivating it. With crudest wooden and bone tools they developed an agriculture that in some respects surpassed that of most white farmers at present in that area.

Maize, sunflowers, beans, squashes and tobacco were raised by the Hidatsas, but their principal crop was maize. The chief varieties of maize were white and yellow flint, "sweet corn," and those producing white and yellow meal. Corn planting began when the wild gooseberry came to full leaf. The corn hills were prepared with digging-stick and bonebladed hoe. The earth was raked over the seed and patted down with the hands. Each corn hill stood exactly where a hill had stood the year before. The fields were hoed twice during the summer. The second hoeing was accompanied by hilling up.

Corn was husked in the field. Friends and relatives commonly joined in a husking bee. Fine full ears were braided in strings; and from these strings, carefully dried, seed ears were chosen for the next year. A provident family kept two years' seed on hand, in order that the ill-favored grain of a poor year might not have to be sown. In the selection and preparation of seeds of all their cultivated crops, these Hidatsa Indians were far more careful than most of our American farmers. The braided strings of ears were transported from the field to the village on the backs of ponies. Smaller loose ears were borne in baskets on the backs of the women; these smaller ears made the main part of the harvest. Before each lodge stood a drying stage, a rather elaborate structure floored with planks split from cottonwood trees. On this floor the loose ears were spread to dry. The braided strings were hung on a railing above, and were bound closely in small bunches to prevent the wind from shelling the drying grain. When well dried the smaller ears were threshed or shelled, and this threshed grain and the braided ears were stored and sealed in jug-shaped caches or pits dug in the ground. Green corn, after having been boiled, shelled and dried, was stored in the caches in bags. Curiously, sweet corn, or "gummy corn" as the Indians call it, was never boiled green. It was prepared by parching, after having become thoroughly ripe.

Fallowing of fields was practised by the Hidatsa agriculturists, and they knew that wood ashes increased the yield of a field. When new ground was cleared the felled trees and bushes were spread over the field and burned for the sake of the ash.

While most of the field work was done by the women, the men assisted in part of the labors. They aided in clearing the fields, and did the heary lifting when a stage was built. However, it was thought that a younger man was better employed hunting, or warring. But when the men's hunting and war days were over they thought it no shame to help their women plant and hoe. Field work was done in the early hours of the day, the women commonly rising with the sun, and returning to the village to eat and rest about ten o'clock in the forenoon.

Seed corn from the most intelligent and skilled of the Hidatsa women is being sold to northwest farmers by a commercial seed house. This fact and the breeding experiments by scientific experimenters bid fair to make another contribution to American economic life by the Indian. 
The thesis is being printed by the University of Minnesota.

\section{Albert Ernest Jenks}

\section{SPECIAL ARTICLES}

\section{THE CHEMICAL CONSTITUTION OF CHITIN ${ }^{1}$}

THE prevalent ideas concerning the molecular structure of chitin have been based upon the fact that it gives off acetic acid when acted upon by strong reagents, such as concentrated acid or alkali, and that its elementary composition suggests the empirical formula $\mathrm{C}_{8} \mathrm{H}_{15} \mathrm{NO}_{6} .{ }^{2}$ Since it is also known that chitin yields on decomposition glucosamin it was a logical inference that the above formula represents an acetylated glucosamin

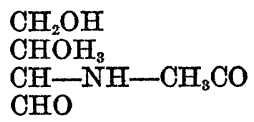

of which chitin is the polymere.

This hypothesis regarding the structure of chitin has been strengthened by other observations, viz., that if chitin is dissolved in strong sulphuric acid, allowed to stand several days and then diluted with a large quantity of water, a white precipitate is formed which on analysis proves to be a monoacetylglucosamin. Occasionally, however, a substance is isolated which represents a monoacetyldiglucosamin.

An investigation upon chitin of lobsters which I conducted recently at the Woods Hole Fisheries Biological Laboratory brought out certain facts which indicate that, while the observations and analyses mentioned previously are doubtless correct, the hypothesis to which they gave origin is based largely upon misconception. I shall present here a brief outline of the principal results of the investigation, reserving a more detailed statement for publication in the near future.

It will not be necessary in this preliminary

1 Published with the permission of the Commissioner of Fisheries.

2 The formula actually computed from the analytical data is $\mathrm{C}_{8} \mathrm{H}_{14} \mathrm{NO}_{6}$, but $\mathrm{C}_{8} \mathrm{H}_{15} \mathrm{NO}_{8}$ is the one usually given because it corresponds to the hypothesis. note to discuss the experimental procedure beyond the mere statement that pure chitin was hydrolyzed with varying strengths of sulphuric acid, and for varying lengths of time, the cleavage products as well as the volatile substances formed during hydrolysis having been quantitatively determined.

The results of fundamental significance yielded by this investigation are the following:

First. Very little volatile acid is formed in the early period of hydrolysis of chitin, though all its glucose molecules may already be split off. A very large production of volatile acid is invariably found when the sugar molecule itself is attacked by the acid medium.

Second. The volatile acid produced is not acetic only. At least in one experiment it was possible to show that two per cent. of the acid was formic. There is good reason for believing that other volatile acids, too, may be formed, but the attempt at isolating and identifying those has not yet succeeded.

Third. The maximum yield of sugar is about 81 per cent.

Fourth. The amino group is readily split off from the glucosamine. The hydrolyzed material contains the ammonium sulphate which can be distilled off directly by making it alkaline, and the ammonia can be collected in standard acid.

Fifth. The nitrogen of the amino group does not represent the total nitrogen in the chitin molecule. There is another nitrogenous part in the molecule which is characterized by great resistance, so that the nitrogen of that small fraction can be obtained only by digesting with concentrated sulphuric acid. There is a remarkably constant relation between this easily detachable nitrogen group and the stabile nitrogen fraction. In my experiments, the latter formed 12.04 to 12.45 per cent. of the total nitrogen.

The interpretation of these results is very obvious. The chitin molecule is certainly more complex than previously assumed. It may be regarded as consisting of two parts: one containing all the glucose and all the amino groups, the other being a stable nitrogenous compound which yields no glucose. It would be venturesome at this time to express an 